\title{
Canada's Population in a Global Context: An Introduction to Social Demography
}

\author{
Frank Trovato \\ Toronto: Oxford University Press. 2009. \\ ISBN: 9780195419078. \\ Price: \$55.95. $x v+646 p p$. \\ Wayne W. McVey, Jr. \\ Professor Emeritus \\ Department of Sociology \\ University of Alberta \\ Edmonton, Alberta. Canada \\ E-mail: wmcvey@ualberta.ca
}

While previous Canadian population textbooks have focused on this country's population in an historical context, this textbook has opened a new road in the understanding of Canadian population. The author has opened an important dimension in the study of Canadian population by exploring and reviewing Canadian population trends in an international context.

The Demographic Bases of Canadian Society by Kalbach and McVey published in 1971 opened the door in the presentation and analysis of Canadian population trends since Confederation. Other editions published in 1979 and 1995 continued to update these trends. The more recent analysis of Canadian population trends was provided in the 2004 second edition of Population Change in Canada by Roderic Beaujot and Donald Kerr. Frank Trovato's book raises the bar by updating and analyzing Canadian fertility, mortality, nuptiality and migration in a comparative perspective with population data of other countries, as well as providing in a global context basic demographic models and theoretical perspectives.

This text is divided into five major parts. The first part commences with explaining population as a scientific discipline and by reviewing population history, demographic transition theory and basic population data sources. The second part then presents demographic composition by discussing age and sex structure and nuptiality. This is followed by two parts dealing with the basic population variables of fertility, mortality and migration. The final part focuses on population change and societal interrelationships including urbanization, resources and policy concerns. This text concludes with an appendix that 
portrays the actual census and vital registration forms, a glossary of demographic terms and an extensive reference list.

As with any text that bridges social and statistical aspects of a subject there will be aspects that will require intensive effort on the part of the instructor to provide further explanation to students. For example, Figure 1.6 presenting age, period and cohort as mechanisms of demographic change would require a more illustrative population examination of these processes. The figure (6.1) concerning Post-WWI cohorts on page 215 would need a knowledgeable instructor to "walk" the student through the major events that influenced the fertility boom and subsequent decline.

Of course, there are many facets in this text that do provide additional understanding of the social implications of demographic change. The inclusion of an illustrative day in Canada with respect to the number of people who marry and divorce, who are born, and the number who die (p. 39); the highlights in the development of national vital statistics (p. 45); the explanation of demographic aging (p. 117); the discussion of the sex ratio imbalances in China (pp. 118119); the explanation of the baby boom and baby bust, (p. 230); and Table 12.3 portraying major population concerns of developed and less developed countries (p. 545) are just a few. These are very important inclusions that aid in explaining the importance of demographic processes in Canada. Other positive elements are the applied population exercises and the web resource listings at the end of each chapter.

The importance of this book rests with its focus on the global comparison with Canada. International data sets are presented in the analysis of the basic demographic processes of fertility, mortality and migration, as well as nuptiality and urbanization. The second essential aspect of this text is that the author has also focused attention on the integration of substantive and theoretical perspectives relevant to each chapter from a global perspective. In addition, a thorough examination and exploration of essential technical principles of demographic analysis is integrated in each chapter.

The author has embedded many data tables portraying Canada in the context of developed and less developed countries. This form of analysis allows readers to see Canadian population for the first time in a global context. While the large tables with international data can be overpowering to the reader, the author is to be commended for his simplified and meaningful interpretations of each table. In addition, the blending of news articles contributes to the understanding of the importance of these basic demographic variables to Canadian society.

This textbook would be most suitable for introductory and senior undergraduate population courses at the university and community college level. Given the inclusion of applied exercises, it would be important to have an instructor's manual that would provide instructors with a step-by-step procedural example for each exercise. These applied exercises are extremely 
important as they help the student understand the significance of demographic change and the many implications for Canadian society. Since study questions are only included for the chapters on fertility, mortality, and urbanization, it would be essential to provide all types of test questions for every chapter in the instructor's manual as well. This would assist instructors in the preparation of examination questions for each assigned chapter and make this textbook extremely functional for all levels of population courses and instructors.

Although many policy and social concerns have been brought about by the demographic changes in all countries of the world and are discussed in this international context in the final chapter, the reviewer feels that there should be a separate and closing chapter dealing with these concerns as they impact Canada specifically. With the passage of time, demographic changes have affected Canadian society significantly. For example, concerns dealing with the impending increase in aging of the Canadian population and the effect this has had on marketing, elder care, housing, health facilities, retirement communities, mobility assistance, and changes in media advertising of health products, to name a few. The increase in women participating in the labour force has influenced changes in marital status, age at marriage, singlehood, fertility levels, consumer power, female independence, marketing and again the mass media. All of these changes have had a major impact upon enterprise decisions and policy decisions at all levels. Including such a focused discussion in a final chapter would assist in providing the student a more familiar backdrop for understanding how these important demographic changes have influenced our lives in Canada.

This book is an extremely important addition to our existing collection of population textbooks. It provides a thorough and comprehensive analysis of basic demographic data, methodology and principles in a global context. This global perspective of Canadian population provides a new and welcome dimension in the understanding of demographic change and its impact on the world. 